\title{
Óbito por leishmaniose visceral em puérpera no município de Palmas, Tocantins, Brasil
}

\section{Death due to visceral leishmaniasis in puerperium in the municipality of Palmas, Tocantins, Brazil}

\author{
Éldi Vendrame Parise ${ }^{1}\left(\mathbb{D}\right.$, Fabiane Sales Coelho Maia ${ }^{1}$ (D) , Nabia Souza Gomes ${ }^{1}$ (D) , Ana Cristina Pereira da Silva ${ }^{1}$ (D) \\ 1. Superintendência de Atenção Primária e Vigilância em Saúde da Secretaria Municipal de Saúde de Palmas (SMS), Palmas, T0, Brasil.
}

\begin{abstract}
Resumo
Relato de caso: neste estudo, foi relatado um óbito por LV, ocorrido em uma puérpera, no município de Palmas, Tocantins, cuja enfermidade não foi identificada durante a gestação, tampouco no período em que permaneceu hospitalizada; evidenciados os fatores que contribuíram para a letalidade do caso; e discutidas as formas adequadas de manejo. Conclusão: por meio de investigação rigorosa nos registros clínicos, laboratoriais e informações junto à família, foi detectada ausência de informações nos prontuários médicos, falhas no monitoramento da paciente, dificuldades de reconhecer um quadro grave de LV em puérpera e, com isso, a necessidade de atualização dos profissionais de saúde com relação à análise clínica e laboratorial, a fim de que haja uma avaliação mais apurada dos sintomas, detecção precoce das complicações, diagnóstico rápido, tratamento adequado e evitar a ocorrência de óbitos.
\end{abstract}

Palavras-chave: Leishmaniose visceral. Morte Materna. Gestante. Puérpera.

\begin{abstract}
Case report: In this study, a death due to LV occurred in a puerpera, in the municipality of Palmas, Tocantins, whose disease was not identified during pregnancy, nor during the period in which she was hospitalized evidenced the factors that contributed to the lethality of the case; and discussed the appropriate forms of management. Conclusion: A rigorous investigation in the clinical, laboratorial and family records revealed a lack of information in the medical records, failure to monitor the patient, difficulties in recognizing a severe VL in the puerperium, and with this, the need for updating of health professionals with respect to clinical and laboratory analysis, in order to have a more accurate evaluation of symptoms, early detection of complications, rapid diagnosis, adequate treatment and avoiding the occurrence of deaths.
\end{abstract}

Key words: Visceral leishmaniasis. Maternal Death. Pregnant. Puerpera.

\section{INTRODUÇÃO}

As leishmanioses são um complexo de doenças zoonóticas parasitárias causadas por um grupo de protozoários trypanosomatideos do gênero Leishmania sp, que possui um ciclo de vida heteroxênico, alternando-se entre hospedeiros vertebrados e insetos vetores ${ }^{1}$. Devido à ampla distribuição, encontra-se entre as seis endemias consideradas prioritárias no mundo ${ }^{2}$, pois estima-se que cerca de 350 milhões de pessoas estão em risco de contrair leishmaniose e 2 milhões de novos casos a cada ano ${ }^{1}$.

Na América Latina, a leishmaniose visceral (LV) já foi descrita em 12 países, sendo que $96 \%$ dos casos ocorrem no Brasil ${ }^{3}$, em 21 Unidades da Federação, com autoctonia em 1/4 dos municípios, especialmente na Região Nordeste, sendo considerado um desafio à saúde pública ${ }^{4}$.

É uma das doenças tropicais mais negligenciadas no mundo caracterizada pelo amplo espectro clínico que varia desde sinais leves ou moderados até manifestações graves com evolução para óbito. Na forma ativa, apresenta-se como uma enfermidade sistêmica, crônica, com febre irregular de longa duração, hepatoesplenomegalia, linfadenopatia, emagrecimento, edema e debilidade, associada a alterações laboratoriais, como citopenias, hipergamaglobulinemia e hipoalbuminemia ${ }^{6}$.

A suspeita diagnóstica baseia-se em dados clínicos, epidemiológicos e achados laboratoriais, e sua confirmação depende da observação de parasitos no exame parasitológico direto e/ou cultura; reação de imunofluorescência indireta (IFI) com título de 1:80 ou mais; teste rápido imunocromatográfico reagente ${ }^{2}$.

Durante o período gestacional, a ocorrência de LV é considerada um evento raro e não existe estimativa da incidência neste grupo de pessoas, mesmo nas áreas endêmicas, principalmente em função de reduzidas publicações científicas ${ }^{2,7}$, sendo que

Correspondente: Éldi Vendrame Parise. Secretaria Municipal de Saúde de Palmas (SMS), Palmas, TO, Brasil. Endereço: 106 Sul, Alameda 14 , lote 06. Palmas, Tocantins. CEP: 77020-062. E-mail: eldiparise@gmail.com

Conflito de interesse: Não há conflito de interesse por parte de qualquer um dos autores.

Recebido em: 17 Maio 2018; Revisado em: 16 Dez 2018; 14 Jan 2019; Aceito em: 16 Jan 2019 
são os casos relatados que auxiliam na elucidação das formas adequadas de manejo da doença, ajudam no esclarecimento das complicações nas gestantes, neonatos e podem evitar óbitos ${ }^{8}$.

Este estudo teve como objetivo relatar um óbito por LV ocorrido em puérpera, no município de Palmas, Tocantins; evidenciar os fatores que contribuíram para a letalidade do caso; e discutir as formas adequadas de manejo da doença, a fim de contribuir com a literatura médica brasileira na divulgação dos cuidados que devem ser dispensados com relação à LV em gestantes.

\section{RELATO DO CASO}

\section{Aspectos clínicos e epidemiológicos}

Paciente FOS, 33 anos, residente em Palmas, Tocantins, compareceu ao Centro de Saúde da Comunidade (CSC) de referência em 18/5/2016, com queixas de enjoos e atraso menstrual. Por meio do exame BetaHCG, foi constatada gravidez e iniciou o acompanhamento pré-natal em 07/6/2016. Informou ser lactante há um ano, usava contraceptivo trimestral e desconhecia o dia da última menstruação. Diante disso, não foi calculada a idade gestacional, mas foi-lhe recomendada a ingestão de ácido fólico, sulfato ferroso, uso de repelente, solicitado exames laboratoriais e ultrassonografia.

A paciente fez seis consultas de pré-natal; e baseado nos prontuários em formato eletrônicos do e-SUS, adotados pela CSC, em nenhuma das consultas foram registradas a anamnese da paciente, resultados de exames físicos, laboratoriais e ultrassonografia; eram realizadas avaliações completas, em que ela se apresentava sem queixas e tratava-se de afecções não especificadas, ligadas à gravidez.

No entanto, durante a investigação de óbito, verificou-se que, em 19/7/2016, foram realizados exames laboratoriais, com resultados normais; em 28/9/2016, ultrassonografia obstétrica, indicando 27 semanas e 6 dias de gestação, líquido normal e uma série de outros exames: toxoplasmose $\operatorname{lgG} 212,6 \mathrm{UI} / \mathrm{mL}$ (reagente $>30,0 \mathrm{UI} / \mathrm{mL}$ ), rubéola IgG 161,20 UI/mL (reagente superior 20,0), toxoplasmose IgM, rubéola IgM, sorologia antiHIV, VDRL para sífilis, marcadores de hepatite (HBs-Ag e Anti $\mathrm{HCV}$ ) não reagentes, glicemia em jejum $79,1 \mathrm{mg} / \mathrm{dL}$ (normal 60,0 a 99,0), hemograma com resultados dentro do recomendado, porém, os elementos e sedimentos anormais da urina (EAS) estavam muito acima dos valores de referência (Tabela 1).

Tabela 1. Evolução dos exames hematológicos e bioquímicos da paciente.

\begin{tabular}{|c|c|c|c|c|c|c|c|c|c|c|c|c|c|}
\hline Exames & $\begin{array}{l}\text { Valores de } \\
\text { referência }\end{array}$ & $28 / 09$ & $27 / 12$ & $29 / 12$ & $01 / 01$ & $13 / 01$ & $22 / 01$ & $24 / 01$ & $25 / 01$ & $27 / 01$ & $28 / 01$ & $30 / 01$ & $31 / 01$ \\
\hline \multicolumn{14}{|l|}{ Hematológicos: } \\
\hline Hemáceas & $4,0-5,5$ tera/L & 3,99 & 3,52 & 4,6 & 3,71 & 2,7 & 2,7 & 2,38 & 2,4 & 3,21 & 3,07 & 2,83 & 3,76 \\
\hline Hemoglobina & $12-16 \mathrm{~g} / \mathrm{dL}$ & 12,3 & 10,3 & 3,4 & 10,7 & 9,9 & 7,7 & 6,9 & 7,0 & 9,6 & 9,2 & 8,8 & 11,4 \\
\hline Hematócrito & $37-47 \%$ & 37,1 & 33,0 & 40,8 & 32,9 & 27,9 & 22,9 & 20,5 & 20,7 & 27,4 & 25,5 & 24,3 & 33,2 \\
\hline RDW & $11-15,1 \%$ & 13,5 & 13,0 & - & - & - & 16,8 & 16,8 & 16,8 & 16,3 & 16,9 & 16,0 & 18,2 \\
\hline Leucócitos & $4,5-10 \times 102 / \mathrm{mm} 3$ & 5.1 & 5.3 & 10.4 & 13.5 & 15.0 & 118.4 & 15.0 & 16.4 & 16.6 & 13.6 & 16.5 & 29.0 \\
\hline Neutr.Totais & $45-75 \%$ & 69 & 85 & - & - & - & 77 & 74 & 70 & 76 & 74 & 71 & 92 \\
\hline Eosinófilos & $1-5 \%$ & 3 & 1 & - & - & - & 7 & 13 & 13 & 10 & 9 & 13 & 1 \\
\hline Linfócitos & $15-45 \%$ & 23 & 10 & 5 & 8 & 6 & 10 & 5 & 8 & 6 & 8 & 8 & 5 \\
\hline Monócitos & $3-10 \%$ & 5 & 4 & 1 & 3 & 4 & 6 & 7 & 9 & 8 & 8 & 8 & 2 \\
\hline Plaquetas & $\begin{array}{c}150-450 x \\
102 / m m 3\end{array}$ & 199 & 198 & 8 & 93 & 196 & 393 & 397 & 402 & 396 & 392 & 353 & 273 \\
\hline \multicolumn{14}{|l|}{ Bioquímicos: } \\
\hline Fosfatase alcalina & $<240 \mathrm{U} / \mathrm{L}$ & - & - & - & 551 & - & - & - & 425 & - & - & - & - \\
\hline TGP & $10-40 \mathrm{U} / \mathrm{L}$ & - & - & 16 & 16 & - & 12 & 11 & 18 & 12 & - & - & - \\
\hline TGO & $10-40 \mathrm{U} / \mathrm{L}$ & - & - & 16 & 23 & - & 58 & 30 & 37 & 58 & - & - & - \\
\hline Bilirrubina total & $<1,2 \mathrm{mg} / \mathrm{dL}$ & - & - & 2,37 & - & - & - & - & - & 1,48 & - & - & - \\
\hline PCR & $<6 \mathrm{mg} / \mathrm{L}$ & - & 5,20 & & - & 9,3 & 11,38 & 19,26 & 19,2 & 18,95 & 18,93 & 17,10 & 18,02 \\
\hline Albumina & $3,5-5,2 \mathrm{~g} / \mathrm{dL}$ & - & - & - & - & - & - & - & 1,6 & - & - & - & - \\
\hline Creatinina & $0,5-1,2 \mathrm{mg} / \mathrm{dL}$ & - & - & 1,0 & 1,0 & 1,1 & 1,9 & 1,8 & 1,8 & 1,6 & 2,4 & 2,8 & 2,0 \\
\hline \multicolumn{14}{|l|}{ EAS: } \\
\hline Ureia & $15-39 \mathrm{mg} / \mathrm{dL}$ & - & - & 52 & 113 & 64 & 164,0 & 156,0 & 148,0 & 156,0 & 155,0 & 152,0 & 110,0 \\
\hline Cél. epiteliais & $<10.000 / \mathrm{mL}$ & 38.750 & 26.000 & - & - & - & - & - & - & - & - & - & - \\
\hline Leucócitos & $4.000-10.000 / \mathrm{mL}$ & 80.000 & 240.000 & - & - & - & - & - & - & - & - & - & - \\
\hline Hemácias & $0-8.000 / \mathrm{mL}$ & 2.751 & 10.000 & - & - & - & - & - & - & - & - & - & - \\
\hline
\end{tabular}


Na quarta consulta pré-natal (25/10/2016), foi prescrita Ampicilina $500 \mathrm{mg}$; na quinta consulta $(28 / 11 / 2016)$ foram repassadas orientações sobre o parto; na sexta consulta (13/12/2016) apresentou sinais vitais estáveis, sem relato de queixas; e o prontuário continuou sem o registro da clínica, hipótese diagnóstica, solicitação e/ou resultados de exames. Entretanto, novamente, no laboratório, havia exames com urocultura negativa e os componentes do EAS todos dentro do normal.

Em 19/12/2016, 39 semanas e 6 dias de gestação, 53 kg, foi admitida no HMDR, às $16 \mathrm{~h} 12 \mathrm{~min}$, com queixas de algia lombar e hipogástrica, cólicas, endurecimento abdominal e sem perdas vaginais. Classificada como risco verde, foi examinada, e por não apresentar trabalho de parto, foi orientada para aguardar em casa. O esposo não concordou e ficaram no hospital esperando o próximo episódio. Às 3h10min (20/12/2016), as dores evoluíram, foi encaminhada ao pré-parto e às $8 \mathrm{~h} 03 \mathrm{~min}$ o bebê nasceu de parto normal, pesando 3.020 gramas, medindo 52 centímetros, sexo feminino, evoluindo para melhora do tônus e boa vitalidade.

No dia seguinte, tranquila, corada, hidratada, acianótica, anictérica, normotensa, eupneica, afebril, diurese normal, porém com dores ao urinar, ausência de evacuação e indisposta. Aceitou dieta alimentar, amamentou o bebê, recebeu apoio e incentivo ao aleitamento materno, houve indicação de sulfato ferroso por três meses e teve alta hospitalar. Um dia depois, apresentou dor abdominal, astenia, inapetência e edema progressivo.

Sete dias após o parto (27/12/2016), procurou a Unidade de Pronto Atendimento Norte (UPA Norte) com histórico de febre há um dia, associada à dor em baixo ventre que piorava durante a lactação. Foi classificada como risco vermelho devido às queixas de dor intensa, taquicardia, hipotensão, temperatura 36,9 으, abdômen globoso e palpação dolorosa na altura uterina. Permaneceu em observação enquanto recebeu uma ampola de Buscopan Composto, $20 \mathrm{mg}$ Tilatil, em $100 \mathrm{ml}$ de soro fisiológico à $0,9 \%$, via endovenosa, e aguardava diagnóstico laboratorial. Às $4 \mathrm{~h} 30 \mathrm{~min}$, os exames indicavam componentes do heritrograma abaixo do ideal e os elementos do EAS muito acima do recomendado (Tabela 1). Hipótese diagnóstica: cistite/nfeç̧ões do trato rinário de localização não especificada. Prescrição: ciprofloxacina 500mg, de 12/12 horas e alta ambulatorial.

Em casa, continuou muito desconfortável, e às $10 \mathrm{~h} 24 \mathrm{~min}$ do dia seguinte $(28 / 12 / 2016)$, dirigiu-se ao HMDR para atendimento de emergência, com queixas de febre, dor abdominal difusa, associada a vômito e febre há três dias, pesando $47,3 \mathrm{~kg}$. Foi realizado procedimento de cateterismo vesical, solicitada radiografia de abdômen e tórax, hemograma e exames para rotina infecciosa, mas logo foi encaminhada ao HGPP para avaliação, com hipótese de apendicite.

Às $12 \mathrm{~h} 50 \mathrm{~min}$, foi admitida no HGPP com os sintomas supracitados, mais ausência de eliminação de flatos e fezes há nove dias, dispneia intensa, peritonite, oligoanúria e taquicardia há um dia. Respirava com auxílio de máscara de Venturi, sonda nasogástrica drenando secreção esverdeada $(300 \mathrm{ml})$; foi realizada lavagem gástrica para estimular o funcionamento intestinal e eliminar resíduos, porém pouco foi expelido. A ultrassonografia de abdômen total revelou hepatoesplenomegalia, com baço levemente aumentado; fígado multinodular com contornos irregulares hiperecoicas, também visualizado na ressonância magnética, porém não foi possível diferenciar entre metástase ou abscesso, pois o exame foi realizado sem contraste, devido ao desconforto respiratório da paciente; havia líquido livre em cavidade abdominal subhepática, sugestivo de sague; útero aumentado de volume compatível com puerpério; ovário direito aumentado e distensão de alças de delgado com conteúdo líquido. Às 23 horas, foi encaminhada à Unidade de Tratamento Intensivo (UTI) com taquipneia, taquicardia, área abdominal distendida, timpânica, ictérica, hipocorada, hipoglicêmica, mas, orientada, afebril, hidratada, acianótica e sem déficit motor. Hipótese diagnóstica: sepse de foco abdominal, infecção puerperal por estafilococos e metástase hepática. Conduta médica: Meropeném, Vancomicina, Metronidazol e solicitado exames laboratoriais.

Em 29/12/2016, os resultados dos exames complementares indicavam hipernatremia, leucocitose, bilirrubinemia e plaquetopenia. Foi solicitado parecer do infectologista, com provável sepse de foco geniturinário, pós-cirúrgico. Em $1 / 1 / 2017$, em estado grave, ecocardiograma com alterações significativas, hemocultura negativa, foi solicitada sorologia para LV, passou a receber ventilação mecânica e foi intubada. Hipótese diagnóstica: síndrome febril após parto a esclarecer, insuficiência cardíaca, quadro sugestivo de miocardiopatia periparto que afeta as mulheres no fim da gestação.

Em 4/1/2017, foi realizada curetagem uterina, em 05/1/2017, recebeu transfusão de quatro bolsas de concentrado de hemácias, em 6/1/2017 realizado procedimento de laparotomia exploradora e em 8/1/2017 apresentou derrame pericárdico, ascite, metástase hepática, síndrome séptica pulmonar, neoplasia, infecção puerperal e hepatoesplenomegalia a esclarecer. No dia 14/1/2017, evoluiu para insuficiência renal aguda (IRA) e pneumonia associada à ventilação mecânica, mesmo fazendo uso de Meropeném (150 dia) e Polimixina B (4ㅇdia). Foram associadas Amicacina e Ciprofloxacina, porém, sem sucesso na clínica, em 16/1/2017 apresentou acúmulo de escórias nitrogenadas. Foram solicitadas traqueostomia, tomografia computadorizada abdominal com contraste e aguardavam o laudo da biópsia hepática guiada por ultrassonografia, requerida em 09/1/2017.

De 18 a 24/1/2017, recebeu mais quatro bolsas de concentrado de hemácias; foi solicitada a reavaliação da cirurgia geral, pois se apresentava estável, continuava com abdômen doloroso à palpação, hepatoesplenomegalia, episódios de febre, estado geral grave, piora da função renal (tabela 1), mas mantinha 
diurese efetiva. Continuou traqueostomizada, sob ventilação mecânica, instável hemodinamicamente, nutrição parenteral exclusiva.

Em 26/1/2017, recebeu, novamente, mais duas bolsas de concentrado de hemácias, pois os elementos do heritrograma estavam abaixo do normal: hemácias 2,4 tera/L (normal 4,6 a 6,0 tera/L), hemoglobina 7,0 g/dL (normal 12 a $16 \mathrm{~g} / \mathrm{dL}$ ) e hematócritos 20,7\% (normal 35 a 47\%), enquanto os leucócitos

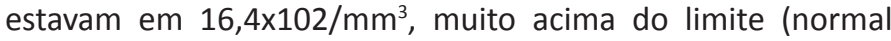
4,5 a 10x102/mm3). Os exames relacionados à função renal (creatinina e ureia) indicavam suspeita de septicemia, ao passo que a função hepática apresentava baixos níveis de albumina; TGO normal; mas, TGP, bilirrubina, fosfatase alcalina e PCR elevados (Tabela 1). Foi prescrita hidroxicloroquina durante cinco dias e solicitada uma avaliação do reumatologista para verificar a possibilidade de doença lúpica. Porém, baseado nos resultados laboratoriais, não havia critério suficiente para lúpus, pois não foram encontrados anticorpos específicos para a doença. Continuou com hipótese diagnóstica de abcesso pélvico e puerpério.

Em 30/1/2017, apresentou instabilidade em vários sistemas orgânicos, incapacidade de responder a estímulos externos, comatoso, hipotensa, congesta, com déficit de oxigenação tissular, síndrome da angústia respiratória aguda (SARA), abdômen com infiltrado (edema na parede geniturinária), IRA e acidose metabólica em urgência dialítica (uremia e edema). Foi suspensa a nutrição parenteral por instabilidade hemodinâmica, solicitada conduta da cirurgia geral (abcesso pélvico) e realizada hemodiálise. No período vespertino e noturno, apresentou duas paradas cardiorrespiratórias, e às $4 \mathrm{~h}$ (31/1/2017) foi acometida de novo episódio, revertido após manobra avançada de reanimação cardiopulmonar; continuou gravíssima, Glasgow 8, descorada, taquicárdica e pulmões com roncos difusos. Às 8h50min, não respondeu mais às manobras de ressuscitação. Na declaração de óbito, constaram, como causa da morte, "choque séptico e infecção puerperal".

Quando os profissionais da vigilância iniciaram a investigação do óbito, foi encontrado, no GAL o resultado da IFI, com título de $1 / 80$, solicitado pelo HGPP em $1 / 1 / 2017$, liberado em $11 / 1 / 2017$, e um teste rápido positivo com data de $2 / 1 / 2017$.

\section{Aspectos ambientais}

No reconhecimento geográfico realizado na área de residência da família, verificou-se tratar de uma região urbana, situada no Plano Diretor Norte de Palmas, de localização melhorada. A quadra é asfaltada, bem arborizada, com alguns terrenos baldios, paralela a uma área verde que dá acesso ao lago formado pela construção da Usina Hidrelétrica Luiz Eduardo Magalhães.

A residência localiza-se em uma esquina, possui árvores frutíferas no quintal (mangueira e coqueiro), casa com paredes de alvenaria, cercada com tijolos e calçadas laterais para pedestre de cimento, porém, perpendicular à sua frente, os passeios permanecem em ambiente natural, com muitos arbustos e árvores.

$\mathrm{Na}$ ocasião do reconhecimento geográfico, foi avistado um cão errante circulando, livremente, na frente da casa e, nas ações de inquérito sorológico canino, executadas pela equipe de controle de zoonoses foram identificados 45 exames de enzimaimunoensaio (ELISA) reagentes para calazar. Entretanto, não foram realizadas coletas entomológicas, no domicílio e peridomicílio, para identificar a presença de flebotomíneos na área, nem o bloqueio de foco com a utilização de inseticida químico, devido à falta de materiais e equipamentos necessários; embora a ação estivesse prevista no Plano de Ação para Vigilância e Controle das leishmanioses.

Segundo informações extraídas do Sinan-Net, nessa quadra foi registrado um caso de LV humana, somente em 2013. Alicerçados em dados trienais, no ano de 2016, a Unidade de Vigilância e Controle de Zoonoses (UVCZ) responsável para realizar ações de monitoramento e vigilância ambiental, estruturou um Plano de Ação para o Controle das Leishmanioses no município de Palmas, e nele, a quadra ficou classificada como sem transmissão humana, uma vez que no triênio não havia registro de nenhum caso humano autóctone. Destacamos que a programação das ações seguiu as orientações da Secretaria de Estado da Saúde do Tocantins e foi pactuada junto a Comissão Intergestores Bipartite e Conselho de Saúde, para garantir que as ações de manejo ambiental, inquérito sorológico canino e controle de reservatórios fossem realizados em conformidade com as áreas de maior risco de transmissão. Para delinear as estratégias de operação, buscaram-se informações junto ao Sistema de Informação de Localidades (SISLOC), em que ficou constatado que, naquela quadra, havia uma população de 119 cães, e isso, é considerado relevante para a manutenção do ciclo da transmissão da doença. Destacamos que o SISLOC é um sistema de armazenamento de informação, cujos dados são coletados pelos Agentes de Endemias, por meio do preenchimento de formulários, com a finalidade de manterem atualizadas, anualmente, todas as informações das áreas geográficas.

Ao perguntar ao esposo sobre o exame de LV positivo registrado no laboratório, respondeu que não estava sabendo nada sobre isso, que em nenhum momento foi cogitada junto à família a possibilidade de ela estar com essa doença, nunca tiveram cachorro em casa, na família não houve e nem há conhecimento de nenhum caso próximo que tenha adoecido por LV. No entanto, ao investigar junto aos vizinhos, ficou evidenciado que FOS estava muito magra ( $47 \mathrm{~kg}$ ), demonstrava fraqueza, olhos fundos, pele brilhante e que, no bairro, sempre teve muitos cães errantes.

\section{DISCUSSÃO}

A LV é uma doença de transmissão vetorial com ampla distribuição no mundo ${ }^{1}$. Estima-se em 200 a 400 mil casos novos a cada ano no mundo; cerca de $10 \%$ evoluem para óbito, 
principalmente em pessoas que vivem em situação de pobreza e vulnerabilidade social ${ }^{4}$.

Em Palmas, de 2007 a 2016, foram registrados 271 casos de LV, dos quais $33,95 \%$ foram do gênero feminino e apenas três em gestantes. A maior incidência foi em 2009 com 20,14/100.000 habitantes e a menor em 2014 com 5,27/100.000 habitantes; coeficiente bem superior ao que foi registrado no Brasil nesse mesmo ano ${ }^{6}$.

Segundo o Ministério da Saúde, a LV em gestante é considerada uma ocorrência rara. Todavia, com a expansão da doença para áreas periurbanas e urbanas, onde os adultos em geral não tiveram exposição prévia à Leishmania sp, têm sido notificados alguns casos em mulheres durante o período gestacional. Esses casos ocorrem devido às migrações populacionais para áreas endêmicas e à presença de vetores, animais domésticos e silvestres, infectados pelo parasito ${ }^{2}$.

Quanto à FOS, já nas primeiras avaliações realizadas no CSC de sua referência, no mês de maio/2016, ficou constatado que se tratava de uma gravidez. Em junho, iniciou o acompanhamento pré-natal, foi orientada, foram solicitadas ultrassonografia e uma bateria de exames laboratoriais, conforme recomendado para uma assistência pré-natal adequada ${ }^{9}$. Nos prontuários eletrônicos, não houve registro que evidenciasse de qualquer afecção específica, que não fossem sinais e sintomas ligados à gravidez, e também não ficaram registrados os resultados dos exames laboratoriais e da ultrassonografia solicitados pelo médico, gerando dúvidas se realmente haviam sido realizados e avaliados, mas posteriormente, foram encontrados durante a investigação do óbito.

Diante disso, ficou constatado que os registros nos prontuários eletrônicos do e-SUS Atenção Básica (e-SUS AB), no CSC de referência da paciente, deixaram muito a desejar. Os dados sobre o atendimento da paciente foram ínfimos. Tanto que as informações relatadas neste estudo sobre os exames do período pré-natal referem-se às investigações realizadas pelos enfermeiros e técnicos da vigilância em saúde. Segundo Resolução do CFM no 1.638 (2002), o prontuário médico é um documento de caráter legal, sigiloso e científico, cujo registro das informações, sinais e imagens, geradas a partir de fatos, acontecimentos e situações sobre a saúde do paciente e a assistência a ele prestada, são obrigatórios, pois possibilitam a comunicação entre membros da equipe multiprofissional e a continuidade da assistência prestada ao indivíduo ${ }^{10}$. Por causa disso, o prontuário eletrônico foi considerado um avanço na saúde; mas, para que de fato represente relevância aos gestores, profissionais de saúde e aos cidadãos, faz-se necessário que a equipe de profissionais esteja treinada e comprometida com a causa, pois é fundamental que o programa seja alimentado e atualizado constantemente ${ }^{11}$.

$\mathrm{Na}$ análise dos fatos, verificou-se que, no mês de outubro, foi prescrita Ampicilina $500 \mathrm{mg}$. Possivelmente, baseada nos exames laboratoriais do dia $28 / 9 / 2016$, visto que os resultados do EAS se apresentavam alterados (tabela 1), indicativo de algum processo inflamatório, infeccioso ou traumático. Porém, no mês seguinte, novos exames indicavam que a infecção estava controlada.

A paciente fez seis consultas pré-natais, o mínimo preconizado pela Portaria no $569 / 2000^{12}$ e passou toda a gestação sem apresentar manifestações clínicas compatíveis com LV, semelhante ao primeiro caso em gestante relatado na Índia por Low e Kooke, em 1926, citado por Palasson (2009), em que os autores descrevem a dificuldade em confirmar o diagnóstico da doença na paciente e no recém-nascido ${ }^{8}$; outro caso relatado em Bangladesh, segundo o qual, no final da gravidez a mãe estava assintomática, porém duas semanas após o parto procurou atendimento médico com leucopenia, linfocitose, hepatoesplenomegalia, testes imunocromatográfico positivo para leishmaniose e seu bebê febril desde o nascimento ${ }^{13}$; e, mais um caso relatado na Alemanha, em que a mãe estava saudável durante a gravidez, não tinha histórico de doença, nem apresentou quaisquer achados patológicos, porém, depois de oito meses, foi detectada transmissão congênita de $\mathrm{LV}^{14}$. Esses resultados ratificam a informação de que a Leishmania sp ou alguns de seus antígenos podem estar presentes no organismo durante um longo período, depois da infecção inicial, e somente uma pequena parcela de indivíduos infectados passam a desenvolver os sintomas da doença ${ }^{1,2}$.

Durante o acompanhamento médico, foi solicitada somente uma ultrassonografia no 1 을 trimestre gestacional, enquanto a OMS preconiza três exames (1으, 2으 e 3 o trimestre). A 1 a que deve ser realizada entre a 11 e a 14 semana, para verificar a viabilidade, idade gestacional, determinação da corionicidade em gemelar e translucência nucal; a 20 a ser realizada entre a 20 a 24 semanas, para avaliar a morfologia fetal; e a 3 ㅇ realizada entre a 32 a 36 semanas, para avaliar o crescimento, placenta e vitalidade $^{15}$. No entanto, na revisão sistemática disponibilizada pela biblioteca Cochrane, não há benefícios da ultrassonografia de rotina em gestações de baixo risco após 24 semanas de gravidez, sendo indicadas apenas para gestações de alto risco e nos casos selecionados para rastreamento de anomalias congênitas e cromossômicas ${ }^{16}$, o que não foi o caso da paciente em estudo, já que durante o acompanhamento pré-natal, não se evidenciou nenhuma complicação relacionada à gestação, e os sintomas da LV se manifestaram somente após o nascimento da criança. Além disso, Pinheiro (2017) descreve que, em locais com estrutura e acesso limitado de recursos médicos e se não houver queixas ou fatores de risco, apenas uma ou duas avaliações ultrassonográficas são suficientes durante toda a gravide ${ }^{17}$.

FOS iniciou um quadro de dor abdominal difusa, associado a vômito e febre, três dias após o parto e, no oitavo dia apresentava abdômen globoso e doloroso à palpação, características da forma ativa da LV. Quando admitida no hospital para internação, já apresentava dispneia intensa, peritonite, oligoanúria, taquicardia, similar aos estudos realizados em Campo Grande, MS, onde quatro puérperas tiveram os sinais e sintomas de LV 
iniciados no período gestacional, mas a infecção foi confirmada após o parto ${ }^{8}$. No caso em estudo, possivelmente, o início dos primeiros sintomas, como febre esporádica, palidez cutânea e dores abdominais, não foram levadas em consideração nas avaliações médicas, porque a paciente havia passado pelo período gestacional e dado à luz há poucos dias. Enquanto isso, a doença avançou, sem, no entanto, desvendar o verdadeiro agente etiológico que causou o óbito.

O exame de ultrassonografia abdominal (28/12/2016) revelou o baço levemente aumentado, características estas já evidenciadas em outros pacientes de LV²; apresentou hepatoesplenomegalia, fígado multinodular, abdômen distendido, hipocorada, ictérica, cujas manifestações são evidentes para leishmaniose e semelhante ao relato de caso descrito por Haque et al. $(2010)^{13}$. Apresentou também, hemorragia, anasarca e ascite, caracterizada pela equipe médica como um líquido na cavidade abdominal sugestivo de sangue, e citado pelo Ministério da Saúde (2014) como sinais e sintomas característicos de LV². No entanto, baseados nessa clínica, no dia 26/1/2017 foi solicitado o parecer do reumatologista para avaliar a possibilidade de doença lúpica e prescrito hidroxicloroquina, um antimalárico também indicado para controlar sintomas do lúpus eritematoso sistêmico, aliviar inflamação, inchaço, rigidez e dores nas articulações $^{18}$.

Segundo informes da SVS/MS, a suspeita diagnóstica de LV deve basear-se em dados clínicos, epidemiológicos e achados laboratoriais. Caso não seja feito o diagnóstico e tratamento da doença, o episódio evolui gradativamente, até apresentar comprometimento mais intenso do estado geral, como anasarca, hemorragia, icterícia, ascite e complicações de natureza infecciosa bacteriana dos tratos urinário, respiratório, que poderão desenvolver um quadro séptico de evolução fatal, pois, frequentemente, fazem uso de antimicrobianos sem resposta clínica ${ }^{2}$; semelhante ao que aconteceu com a paciente em estudo, visto que a medicação administrada não produziu os efeitos desejados.

Nos exames complementares, o heritrograma indicava um estado anêmico; a fosfatase alcalina, a bilirrubina e o TGO apresentavam-se alterados, compatíveis com sinais e sintomas de LV; porém, as plaquetas ficaram baixas apenas no início da hospitalização, depois normalizaram, corroborando com os relatados do Ministério da Saúde². Já, os componentes do leucograma apresentavam uma leucocitose neutrofílica; houve aumento da creatinina e uma exorbitância nos resultados da ureia, contrariando os informes da SVS/MS para LV². Segundo Pinheiro (2017), quanto mais alta for a creatinina, mais grave é a insuficiência renal, a qual deve ser tratada com hidratação, suspensão do medicamento agressor ou hemodiálise ${ }^{17}$. A paciente vinha sendo tratada por sepse pulmonar, abcesso abdominal e pélvico e, um dia antes do óbito, foi conduzida para hemodiálise com urgência, seguindo as orientações de que pacientes com edema pulmonar agudo, níveis elevados de potássio no sangue ou acidose metabólica grave precisam de hemodiálise urgente ${ }^{17}$.

Os resultados do PCR também permaneceram alterados durante todo o percurso (tabela 1 ), indicando tratar-se de um quadro infeccioso, de origem bacteriana e que o organismo estava numa batalha intensa na luta contra a doença, evoluindo progressivamente para 0 estado fatal ${ }^{17}$. Possivelmente, originário de uma infecção puerperal que não foi possível controlar, por não ter sido administrada a droga adequada que bloqueasse o desenvolvimento do protozoário flagelado do gênero Leishmania sp, e isso, favoreceu para que o estado geral da paciente entrasse numa cascata à deriva. Um dia antes do óbito, os eosinófilos representaram 13\% de leucócitos, sugestivo de que o organismo estava lutando, também, contra uma infecção parasitária.

Segundo Pinheiro (2017), o exame de PCR além de indicar que havia proteínas agudas produzidas pelo fígado em resposta ao dano tecidual, e sinalizar que se tratava da fase ativa de uma infecção relevante, principalmente de origem bacteriana, também serve para acompanhar a eficácia de um tratamento, pois, um paciente que, após 48-72 horas de tratamento com antibiótico, não apresentar melhora em seu quadro clínico e sinais de queda da PCR, provavelmente precisará de um novo plano de tratamento, pois o atual demonstra não estar sendo eficaz ${ }^{17}$.

Observou-se que, enquanto FOS permaneceu aos cuidados médicos, apresentou derrame pericárdico, passou a receber ventilação mecânica e foi intubada. A equipe médica realizou vários procedimentos médicos: curetagem uterina, transfusão de hemácias, procedimento de laparotomia exploradora, biópsia hepática, ultrassonografia, tomografia computadorizada abdominal, que sempre evidenciavam resultados elevados e indicativos de infecção ativa. Depois de muitas tentativas e não obtendo sucesso com as manobras realizadas, em decorrência da infecção que não respondia aos medicamentos, o quadro culminou com acidose metabólica, complicações urinárias (IRA), sepse pulmonar (SARA) e três paradas cardiorrespiratórias de evolução fatal.

A paciente passou também por e vários exames laboratoriais que evidenciavam infecção ativa, inclusive, em $1 / 1 / 2017$, foi solicitada uma sorologia para LV. Baseado nessa suspeita, o Ministério da Saúde informa que, quando o paciente apresentar febre e esplenomegalia, associado ou não à hepatomegalia, o resultado de um teste rápido reagente, IFI com título de 1:80 ou mais e exame parasitológico direto e/ou cultura positiva, reforçam o diagnóstico ${ }^{2}$. O fato é que, no prontuário médico em que a paciente permaneceu internada (HGPP), não houve registro sobre o resultado do exame para $\mathrm{LV}$, mas, quando a equipe de saúde começou investigar o óbito, foi encontrado, no laboratório municipal, o resultado de uma IFI com título de 1:80 e um teste rápido positivo, liberado no dia 2/1/2017, o que configurou negligência médica, pois, o exame foi solicitado, mas não analisado. Isso representa muita preocupação com 
relação à qualidade dos serviços prestados, pois, se o exame tivesse sido analisado, seria suficiente para confirmar a doença, providenciar a prescrição adequada e reverter todo o quadro apresentado.

O Manual de Vigilância e controle da leishmaniose visceral, elaborado pelo Ministério da Saúde, esclarece que o diagnóstico e o tratamento são decisivos para diminuir as consequências da LV, e nas gestantes, para evitar a transmissão transplacentária ${ }^{2}$. Neste estudo, verificou-se que tanto os exames específicos como os sinais clínicos que evidenciavam ser um caso de LV passaram despercebidos por todos os profissionais que cuidaram da paciente, exceto pelo médico que solicitou sorologia para LV. Porém, ao dar continuidade ao atendimento, falhou também. Por isso, avaliamos o episódio como grave nos serviços de saúde e destacamos a importância de valorizar as queixas das gestantes, ficar atentos aos primeiros sinais e sintomas da LV, a fim de realizar diagnóstico, tratamento precoce e acompanhamento intensivo, principalmente em regiões endêmicas da doença.

Para a SVS/MS, todo indivíduo proveniente de área com ocorrência de transmissão e que apresentar clínica, deve ser suspeitado para $L^{2}$. O caso, em estudo, fixava residência em um bairro que apresenta condições favoráveis à proliferação de vetores transmissores da doença, pois, paralelo à quadra, existia uma extensa área verde mantida como de preservação natural que dá acesso ao lago, uma população canina considerável, inclusive, circulação de cães errantes.

Embora, neste bairro, o último registro da doença em humanos tenha sido em 2013, no ano de 2016, o município foi classificado como de transmissão intensa para LV. Nas ações de vigilância, foram realizadas 4.534 sorologias caninas pelo método enzimaimunoensaio, das quais, 3.076 (64,84\%) foram reagentes. Destas, 277 foram em cães da quadra de residência da paciente e $45(16,25 \%)$ reagentes para calazar. Diante disso, constatou-se que o local em estudo é considerado insidioso para a doença e, por isso, as ações de vigilância envolvendo o ambiente, o homem, o vetor e a população canina devem ser realizadas ininterruptamente.

No entanto, no ano de 2016, em Palmas, foram priorizadas atividades de bloqueio nas áreas de maior risco para LV, direcionadas por um Plano de Ação que se baseou em dados do último triênio. Por isso, no bairro em estudo, foram realizadas: coletas de sorologia canina, os cães positivos foram recolhidos pela UVCZ, de acordo com o cronograma diário de execução, e o manejo ambiental realizado rotineiramente pelos Agentes de Endemias. Porém, a pesquisa entomológica e o bloqueio de foco, por meio da aplicação de inseticida químico residual, não foram realizados devido à falta de materiais e aos equipamentos adequados para o trabalho, o que representou falha nas ações de vigilância ambiental.

Segundo Jayme et al., (2016), no Tocantins, as características ecoepidemiológicas, manutenção de hábitos simples e atividades ligadas às matas, como criação de animais nos quintais, soltos nas ruas, resíduos de florestas no perímetro urbano, intenso fluxo migratório e a falta de estrutura básica e sanitária propicia a urbanização e a propagação da doença ${ }^{19}$.

Diante disso, ficou destacado o risco potencial da ocorrência de casos graves, por consequência da falta de diagnóstico precoce e tratamento adequado. Evidenciou-se a deficiência de informação nos prontuários médicos, a necessidade de uma avaliação mais apurada por parte dos profissionais de saúde com relação às manifestações clínicas e resultados laboratoriais para LV, e com isso, a urgência de promover cursos de atualização aos médicos e enfermeiros para reconhecer precocemente os sintomas da doença e melhorar o monitoramento dos pacientes em tratamento, a fim de identificar precocemente possíveis complicações, reduzir o grau de morbidade, as taxas de letalidade e os riscos de transmissão local. Até porque, um caso de LV em gestante potencializa a transmissão congênita, já que pode acontecer, durante o trabalho de parto, contato do recém-nascido com o sangue da mãe, ou ainda infecção transplacentária ${ }^{14}$, sendo o mais preocupante que a maioria ocorre em gestantes sintomáticas não tratadas ${ }^{20}$.

Quanto à recém-nascida, não foi possível investigar a hipótese de transmissão congênita, pois, logo após o óbito da mãe, ela passou a ser cuidada pela avó paterna, no estado do Piauí. Mas, segundo informações dos parentes, encontra-se bem.

Em Palmas, mesmo com todos os esforços do setor de saúde com relação à vigilância e controle da leishmaniose, em humanos e caninos, há a necessidade de intensificar ações educativas, envolvendo todos os profissionais, a fim de elucidar as dúvidas sobre o agravo, diferenciar os sinais e sintomas da doença, esclarecer a população de que os cães não são os únicos reservatórios da doença e estimular a adoção de medidas preventivas e de controle

\section{REFERÊNCIAS}

1. World Health Organization. Leishmaniasis [internet]. Geneva: WHO; 2017 [acesso 2017 Fev 12]. Disponível em: http://www.who.int/gho/neglected_ diseases/leishmaniasis/en/.

2. Ministério da Saúde [BR], Secretaria de Vigilância em Saúde, Departamento de Vigilância Epidemiológica. Manual de Vigilância e controle da leishmaniose visceral. 5. reimpr. Brasília: Ministério da Saúde; 2014.

3. Organização Pan-Americana da Saúde, Organização Mundial da Saúde (OMS).
Leishmanioses: Informe epidemiológico das Américas. Inf. Leishmanioses [internet]. 2017 Abr [acesso 2017 Maio 10]; 5. Disponível em: http://iris.paho. org/xmlui/bitstream/handle/123456789/34113/informe_leishmanioses_5_ por.pdf?sequence=1\&isAllowed=y.

4. Werneck GL. Controle da leishmaniose visceral no Brasil: o fim de um ciclo?. Cad. Saúde Pública. 2016 Jun; 32(6): eED010616. doi: http://dx.doi. org/10.1590/0102-311X00ED010616. 
5. Fundação Osvaldo Cruz, Agência Fiocruz de Notícias. Doenças negligenciadas [internet]. Rio de Janeiro: Ministério da Saúde; 2013. [acesso 2017 Nov 27]. Disponível em: https://agencia.fiocruz.br/doen\%C3\%A7as-negligenciadas. 6. Brasil. Comissão Nacional de Incorporação de Tecnologias no SUS. Leishmaniose visceral - Protocolo. [internet] 2017 [acesso em 2017 Maio 17]. Disponível em: http://conitec.gov.br/images/Protocolos/Escopo_PCDT_ Leishmaniose Visceral_Enquete.pdf.

7. Figueiró-Filho EA, Duarte G, El-Beitune P, Quintana SM, Maia TL. Visceral leishmaniasis (Kala-azar) and pregnancy. Infect Dis Obstet Gynecol. 2004; 12(1):31-40. doi: 10.1080/104744042000210384.

8. Palasson RR. Leishmaniose visceral e gestação: análise de casos e transmissão vertical no município de Campo Grande, MS, Brasil. [dissertação]. Campo Grande (MS): Universidade Federal de Mato Grosso do Sul; 2009.

9. Ministério da Saúde [BR], Secretaria de Políticas de Saúde. Assistência Prénatal: Manual técnico. 3. ed. Brasília: Ministério da Saúde; 2000. 66 p.

10. Brasil. Conselho Federal de Medicina (CFM). Resolução CFM № 1.638, de 10 de julho de 2002. Define prontuário médico e torna obrigatória a criação da Comissão de Revisão de Prontuários nas instituições de saúde. Diário Oficial [da] República Federativa do Brasil. 2002 Ago 9 [acesso em 2017 Jun 25]; Seção 1, p.184-185. Disponível em: http://www.portalmedico.org.br/resolucoes/ cfm/2002/1638_2002.htm.

11. Rosa, T. E-SUS Atenção Básica é lançado pelo Ministério da Saúde. Rev. Consensus [internet] 2017. [acesso 2017 Maio 31]; (7). Disponível em: http://www.conass.org.br/consensus/e-sus-atencao-basica-e-lancado-peloministerio-da-saude/.

12. Brasil. Ministério da Saúde. Portaria GM/MS no 569, de 10 de junho de 2000. Instituir o Programa de Humanização no Pré-natal e Nascimento, no âmbito do Sistema Único de Saúde. Diário Oficial [da] República Federativa do Brasil. 2000
Jun 8 [acesso 2017 Jun 20]; Seção 1, p. 4-6. Disponível em: http://bvsms.saude. gov.br/bvs/saudelegis/gm/2000/prt0569_01_06_2000_rep.html.

13. Haque A, Ekram ARMS, Sharmin LS, Belaluddin M, Salam MA. Congenital Visceral Leishmaniasis. Pak J Med Sci. 2010 Apr-Jun; 26(2):485-487.

14. Boehme CC, Hain U, Novosel A, Eichenlaub S, Fleischmann E, Löscher T. Congenital Visceral Leishmaniasis. Emerg Infect Dis. 2006 Feb; 12(2): 359-360. doi: 10.3201/eid1202.050449d.

15. Ferlin, RM. Ultrassom no Pré-Natal. [internet] 2017 [acesso em 2017 Maio 25]. Disponível em: http://www.saude.pr.gov.br/ arquivos/File/ACS/ultrassom_ pre_natal.pdf.

16. Noronha C Neto, Souza ASR, Moraes OB Filho, Noronha AMB. Importância da ultrassonografia de rotina na prática obstétrica segundo as evidências científicas. Femina. 2009 Maio; 37(5):239-245.

17. Pinheiro, P. Ultrassonografia na gravidez - quando fazer e para que serve. Md. Saúde [internet]. 2017 Out [acesso em 2017 Jun 8]. Disponível em: http:// www.mdsaude.com/.

18. Meinão IM, Sato El, Andrade LE, Ferraz MB, Atra E. Controlled trial with chloroquine diphosphate in systemic lupus erythematosus. Lupus. 1996 Jun; 5(3):237-241. doi: 10.1177/096120339600500313.

19. Jayme MS, Wanderlei CL, Moura FFM, Castro JGD. Perfil epidemiológico dos casos de Leishmaniose Visceral em Palmas, Tocantins no período de 2007 2014. Rev Pat Tocantins. 2016; 3(1):61-69.

20. Figueiró EA Filho, Uehara SNO, Senefonte FRA, Lopes AHA, Duarte G, El Beitune P. Leishmaniose visceral e gestação: relato de caso. Rev. Bras. Ginecol. Obstet. 2005 Fev; 27(2):92-97. doi: http://dx.doi.org/10.1590/5010072032005000200009

\section{Como citar este artigo/How to cite this article:}

Parise EV, Maia FSC, Gomes NS, Silva ACP. Óbito por leishmaniose visceral em puérpera no município de Palmas, Tocantins, Brasil. J Health Biol Sci. 2019 Jul-Set; $7(3): 312-319$ 